\title{
Outcome of pigs with short gut syndrome submitted to orthotopic intestinal transplantation ${ }^{1}$
}

\author{
Juan Carlos Llanos', Philip Ruiz ${ }^{\mathrm{II}}$, Hidenori Takahashi ${ }^{\mathrm{III}}$, Victor Delacruz ${ }^{\mathrm{III}}$, Alexandre Bakonyi Neto ${ }^{\mathrm{I}}$ \\ DOI: http://dx.doi.org/10.1590/S0102-86502015002000009 \\ ${ }^{\mathrm{I}} \mathrm{PhD}$, Associate Professor, Department of Surgery and Orthopedics, Botucatu Medical School, State University of Sao Paulo (UNESP), Brasil. \\ Manuscript preparation, supervised all phases of study. \\ ${ }^{I I P h D}$, Associate Professor of Surgical Pathology, Division of Transplantation, Department of Immunopathology, University of Miami School of \\ Medicine, Miami, Florida, USA. Histopathological examinations. \\ IIIFellow in Surgical Pathology, Division of Transplantation, Department of Immunopathology, University of Miami School of Medicine, Miami, \\ Florida, USA. Histopathological examinations.
}

\section{ABSTRACT}

PURPOSE: To evaluate the current model of small bowel resection and intestinal transplantation in pigs.

METHODS: Forty two Large White pigs were distributed in five groups: G1(n=6), G2(n=6) and G3(n=6) were submitted to 80\%,100\% and $100 \%$ plus right colon resection respectively and $\mathrm{G} 4(\mathrm{n}=7)$ and $\mathrm{G} 5(\mathrm{n}=5)$ to $100 \%$ SBR plus IT without and with immunosuppression based on Tacrolimus and Mycophenolic acid. Evaluation included weight control, clinical status, biochemical analysis and endoscopies for graft biopsies. Follow-up in G1 and 2 was 84 days, while in G3, four and five was \pm three weeks.

RESULTS: G1 increased weight suggesting adaptation while G2 and 3 loused weight and inadequate adaptation. G4 and 5 died of acute cellular rejection (ACR) and sepses respectively. Overall survival in G1, 2, 3, 4 and 5 at 30 days was 100, 100, 0 and 20\%, respectively. Medium survival in G4 and 5 was 14 and 16 days.

CONCLUSIONS: The resection of $80 \%$ of small intestine in pigs is not suitable for short bowel syndrome induction. Intestinal transplantation with the proposed immunosuppression protocol was effective in prevent the occurrence of severe acute rejection, but inappropriate to increase recipients survival.

Key words: Transplantation. Short Bowel Syndrome. Graft Rejection. Swine. 


\section{Introduction}

Short bowel syndrome (SBS) is characterized by intestinal failure related to extensive small intestinal resections, with an estimated incidence of irreversible intestinal failure of two to five patients per million/habitants ${ }^{1}$.

SBS is not only influenced by the extension or anatomical location of the removed intestine but also by the features of remaining intestine, patient age, presence of ileocecal valve and or colon. The remaining intestine should not only be classified as short by the extension, but also by the absence of adaptation after resection ${ }^{2}$.

SBS is multifactorial and include resections due to gastrosquise, necrotizing enterocolitis, intestinal atresia, abdominal trauma, volvos, abdominal tumors, Crohn's disease, vascular thrombosis and less often by desmoids tumors and megacolon. Intestinal adaptation may occur after resection, with the goal of achieving autonomy. Several studies reported the main changes after intestinal adaptation ${ }^{3,4}$.

Anatomically, SBS is defined in presence of less than $30 \%$ of intestine, being less than $75 \mathrm{~cm}$ in children or $200 \mathrm{~cm}$ in adults ${ }^{5}$.

The treatment is mandatory for all patients with intestinal failure, including multidisciplinary team for venous access evaluation, assessment for enteral or parenteral nutrition, assessment of liver function and early closure of enterostomies whenever possible.

Frequent complications include hidroelectrolite and metabolic disorders, infectious related to central catheters, chronic diarrhea, cholestasis, biliary stones and skin lesions. Messing et $a l .{ }^{6}$ reported $30 \%$ of deaths related to infections among patients receiving home parenteral nutrition, with half of them related to central venous access. It is estimated that $15 \%$ of patients on TPN develop terminal liver disease ${ }^{7}$, related to the procedure ${ }^{8}$.

Several surgical techniques have been described for autologous intestinal reconstruction ${ }^{9-12}$, and more recently, the STEP procedure (Serial Transverse Enteroplasty) ${ }^{13-16}$.

However, Intestinal transplantation emerged as an therapeutic approach in life-threatening complications of ${ }^{17}$, with the type of graft been individualized for each patient (isolated intestine, associated with liver or multivisceral) ${ }^{18,19}$.

The patients and grafts survival in the first year after transplant is similar to as achieved in other organs with the current immunosuppression protocols, including tacrolimus, associated to induction therapy with interleukin-2 blockers, anti-lymphocyte globulin or alemtuzumab ${ }^{20,21}$.
The treatment of rejection is still dependent on the use of no specific immunosuppressive drugs, which can trigger infection complications and lymphoproliferative disorders ${ }^{22}$. Long-term survival have been limited by graft immunogenicity, with rejection and infection as the most common causes of morbidity and mortality ${ }^{23}$.

Thus, experimental research is mandatory for clinical purposes in order to improve the results after transplant. Several experimental models in small animals (rodents) have been described for nutritional, immunological and technical studies in SBS and intestinal transplantation, with limitations in reproduce the conditions observed in humans ${ }^{24}$. The porcine model emerged as the model of choice in several studies, by the physiological and anatomical features similar to humans ${ }^{25}$.

In order to allow a better knowledge of this model, we proposed to evaluate the current model of SBS and intestinal transplantation in pigs.

\section{Methods}

Research was approved by the Animal Ethical Committee of Botucatu Faculty of Medicine, UNESP.

Forty two Large-White / Landrace pigs, weighing 15 to $35 \mathrm{Kg}$ were used, and housed at the Experimental Laboratory for 15 days before the procedures. All animals were fed with a regular laboratory diet for pigs and water and fasted for water and food 2 and 24 hours before the surgery respectively.

\section{Experimental design}

The animals were distributed in five groups according to the procedure: $\mathrm{G} 1(\mathrm{n}=6), 80 \%$ small bowel $(\mathrm{SB})$ resection; $\mathrm{G} 2(\mathrm{n}=6)$, total $\mathrm{SB}$ resection; $\mathrm{G} 3(\mathrm{n}=6)$, total $\mathrm{SB}$ including right colon resection; $\mathrm{G} 4(\mathrm{n}=7)$ and $\mathrm{G} 5(\mathrm{n}=5)$ to a total $\mathrm{SB}$ resection plus orthotopic SB transplantation without and with imunossupresion respectively. In G4 and G5 were used male pigs weighing $15 \pm 7$ $\mathrm{kg}$ as donors and female pigs weighing $25 \pm 10 \mathrm{~kg}$ as recipients. The imunossupression protocol in G5 included $0.2 \mathrm{mg} / \mathrm{Kg} /$ day of tacrolimus and mycophenolate sodium at a dose of $15 \mathrm{mg} / \mathrm{kg} /$ day administered by G-tube four hours before and after the transplant. The doses of tacrolimus were adjusted to maintain the serum levels between 15 to $20 \mathrm{ng} / \mathrm{ml}$, assessed by imunoenzimatic assay. The pre-anesthesia drugs included acepromazina (0.1 $\mathrm{mg} / \mathrm{kg})$, morphin $(0.4 \mathrm{mg} / \mathrm{kg})$, Ketamin $(10 \mathrm{mg} / \mathrm{kg})$ and atropin $(0.044 \mathrm{mg} / \mathrm{kg} \mathrm{IM})$, followed by anesthesia induction with E.V. diazepan and ketamin at the same proportion $(1: 1)$ and doses of 
0.1 to $0.15 \mathrm{ml} / \mathrm{kg}$. A Maggil catheter was inserted in the trachea, connected to a mechanical ventilator with 1 liter/min of $100 \%$ oxigen flow . The anesthesia was maintained in the G1, G2, G3 and donor animals by e.v. xilazin $(1 \mathrm{mg} / \mathrm{ml})$, Ketamin $(2 \mathrm{mg} / \mathrm{ml})$ and éther gliceril guaiacol $5 \%(50 \mathrm{mg} / \mathrm{ml})$, diluted in $250 \mathrm{ml}$ of glucose solution at a rate of $2.0 \mathrm{ml} / \mathrm{kg} /$ hour. In the recipient animals of $\mathrm{G} 4$ and G5, the anesthesia maintenance was carried out by isofluorane at a median 2.5\% (1.7 CAM) concentration. All animals received a warm Ringer Lactate solution during the procedures, at a rate of $10 \mathrm{ml} / \mathrm{kg}$ /hour for median arterial pressure support over $60 \mathrm{mmHg}$. Body temperature was measured by an esophagic sensor.

\section{Surgical technique}

After resection in G1, G2 and G3, intestinal reconstruction was carried out by end-to-end two layers anastomosis. In G1, the resection was realized after entire small bowel measure at antimesenteric border (corresponding to $\pm 17 \mathrm{mts}$ ), leaving a remnant of $\pm 1.5 \mathrm{mts}$ of jejunum and $\pm 1.5 \mathrm{mts}$ of ileum.

The operative technique for the donors and recipients in G4 and G5 has been described previously. Briefly, the entire small bowel was perfused through the abdominal aorta with approximately $500 \mathrm{ml}$. of cold Ringer Lactate solution at $4^{\circ} \mathrm{C}$ with $2500 \mathrm{UI}$ of heparin and harvested from the donors with the superior mesenteric / portal vein and superior mesenteric artery with an aortic conduit. In the recipient, after entire small bowel resection, the graft aortic conduit and vein were anastomosed to recipient infrarenal aorta and superior mesenteric vein respectively. Proximal intestinal continuity of the graft and recipient was restored by side-to-side anastomosis between recipient duodenum and jejunal graft, leaving a terminal jejunostomy at $30 \mathrm{~cm}$ of the anastomosis and distally by an end-to-end anastomosis between the graft and recipient ileum. A gastrostomy was placed for gastric decompression.

After surgery, the animals were transferred to a warm environment and followed for anesthetic recuperation and removal of the tracheal tube.

\section{Postoperative follow-up}

Prophylactic antibiotics $(60 \mathrm{mg} / \mathrm{Kg} / \mathrm{of}$ Cefuroxima C) were administered for two days and analgesic with oral vedaprofeno $\mathrm{H}$ ( $1 \mathrm{ml} / 10 \mathrm{~kg}$ of body weight ) for 2 days or when necessary ( pain or fever ). All animals were fed with water and regular laboratory diet for pigs at postoperative days 1 and 2 respectively. Intravenous saline solution was administered when food or water intake were considered unsatisfactory.

Animal Death before day 3 was considered as technical failures and were not included in this study. The animals were sacrificed when more than $40 \%$ of weight loss was observed in relation to the preoperative body weight or when become lethargic, without activity.

\section{Postoperative clinical assessment}

All animals were daily observed for food intake, nauseas or vomiting, activity, ear and nose colors, diarrhea, skin incision, jejunostomy features and weekly for body weight measurements. Date was collected each week and registered as T1 (1 week after surgery) to T12 (twelve weeks after surgery).

\section{Postoperative endoscopic graft assessment}

For diagnosis of rejection, G4 and G5 animals were submitted to a weekly conventional endoscopy, through the jejunostomy, realized by handling the animals, without anesthesia. Graft biopsies were obtained and processed by a conventional technique and rejection graduated according to the criterions established on Pathology Workshop at the VIII International Small Bowel Transplant Symposium held in Miami ${ }^{26}$ : Grade 0 (without acute cellular rejection), Indeterminate, Grade 1 (mild acute cellular rejection), Grade 2 (moderate acute cellular rejection) and Grade 3 (severe acute cellular rejection).

After animal death, a necropsy was realized and graft samples obtained for histological studies.

\section{Postoperative biochemical assessment}

Laboratory data was collected each week and registered as T1 (1 week after surgery) to T12 (twelve weeks after surgery) and included: total proteins, albumin, cholesterol, triglycerides, urea, creatinin, glycemia, bilirrubins, sodium, potassium, calcium and serum tacrolimus levels.

\section{Statistical analysis}

The significance of differences between means was determined by using the Anova test and the Tukey test when appropriate. The significance of differences in cumulative survival was determined by Kaplan-Meier and log-rank test. Values were considered statistically significant for $p<0.05$. The analysis was performed with Statistical 5.0 software. 


\section{Results}

The cold and warm ischemia time was $118.5 \pm 13.7$ and $163.8 \pm 35.6$ minutes, $51.3 \pm 6.0$ and $46.8 \pm 5.3$ minutes in $\mathrm{G} 4$ and G5 respectively. The time consuming for the entire procedure in the recipients were $177.3 \pm 33.4$ and $236.5 \pm 29.9$ minutes for G4 and G5 respectively. For G1, G2 and G3 the time consuming in the procedure was \pm 120 minutes. The variations in body temperature was significant after graft reperfusion in G4 and G5 ( $<<0.05$ ). The anesthesia in all groups was considered satisfactory, without deaths attributed to the procedure.

\section{Clinical evaluation}

The food intake was considered unsatisfactory in G3, G4 and G5, associated to physical inactivity of the animals. With exception of G1, all animals of the remaining groups presented diarrhea during the follow-up. No gastrointestinal disorders, infections or jejunostomy alterations (in G4 and G5) were observed among the groups.

The weight loss in G2 was slow and progressive, and statistically significant $(\mathrm{p}<0.05)$ after 10 weeks (T10) when compared to animals in G1, where a weight improve was observed. In G3, G4 and G5, the weight loss at T3 was statistically significant $(\mathrm{p}<0.05)$ when compared to T1. Animals in G3 reached the sacrifice criteria's (more of $40 \%$ of weight loss in relation to preoperative body weight ) between third and four weeks after surgery (Table 1).

TABLE 1 - Weight control between groups (Kg).

\begin{tabular}{lccccc}
\hline Weight & T1 & T2 & T3 & T5 & T12 \\
\hline G1 & $25.8 \pm 6.9$ & $27.3 \pm 8.6$ & $28.5 \pm 9.5$ & $31.9 \pm 4.2$ & $44.0 \pm 5.1$ \\
G2 & $33.3 \pm 12.1$ & $31.1 \pm 11.4$ & $29.4 \pm 10.5$ & $26.8 \pm 4.2$ & $23.9 \pm 3.1$ \\
G3 & $22.2 \pm 3.0$ & $17.4 \pm 2.4$ & $14.5 \pm 1.8$ & & \\
G4 & $36.0 \pm 9.3$ & $31.8 \pm 8.5$ & $22.4 \pm 3.8$ & & \\
G5 & $28.3 \pm 5.8$ & $24.9 \pm 4.2$ & $22.7 \pm 5.0$ & $12.5 \pm 2.0$ & \\
\hline
\end{tabular}

T: week; G: group. Weight at G2<G1 after T10 $(\mathrm{p}<0.05)$; Weight at T3 in G3, G4 and $\mathrm{G} 5<\mathrm{T} 1(\mathrm{p}<0.05)$

\section{Endoscopic and histopathological studies}

Endoscopic evaluation of the grafts showed the presence of ulcerations, flat mucosa and changes of color in G4 animals in $57 \%, 71 \%$ and $43 \%$ respectively, starting two weeks after transplant and a normal endoscopic appearance in G5 animals. Histological evaluation of the biopsies in G4 animals demonstrated moderate acute rejection after the first week of the transplant. The occurrence of severe acute rejection was observed in 1 animal in G5 at day 14 after transplant, with histologically recovery of the mucosa in biopsy obtained one week later. The remaining animals in G5 (80\%) showed a histological pattern classified as indeterminate rejection. After necropsy, histological evaluation of the grafts showed severe acute rejection in G4 animals and unspecific alterations classified as indeterminate and mild acute rejection in $40 \%$ and $60 \%$ in G5 respectively.

\section{Biochemical evaluation}

With exception of G1 and G2 animals, where a slow decrease in the mean total proteins was observed during the 12 weeks follow-up (Table 2), all animals from the remaining groups showed an increase between T1 and T3, statistically significant in G2,G3 and G4 $(p<0.05)$. A tendency of decrease in albumin mean levels (Table 3) was observed in G1 between T1 and T12, that was significant $(\mathrm{p}<0.05)$ in $\mathrm{G} 2$ animals, probably related to a chronic malnutrition of the animals. A significant decrease $(\mathrm{p}<0.05)$ was observed at T3 in G4 and G5 animals when compared to G1 and G2.

TABLE 2 - Total proteins between groups (g/dl).

\begin{tabular}{lccccc}
\hline Total Protein & T1 & T2 & T3 & T5 & T12 \\
\hline G1 & $6.8 \pm 0.4$ & $6.6 \pm 0.5$ & $6.5 \pm 0.4$ & $6.3 \pm 0.6$ & $6.0 \pm 0.3$ \\
G2 & $6.4 \pm 0.5$ & $7.9 \pm 0.6$ & $7.4 \pm 0.8$ & $6.4 \pm 0.4$ & $5.6 \pm 0.7$ \\
G3 & $5.5 \pm 0.5$ & $6.5 \pm 0.6$ & $6.6 \pm 0.8$ & & \\
G4 & $6.3 \pm 0.6$ & $7.2 \pm 0.7$ & $7.3 \pm 0.5$ & & \\
G5 & $6.9 \pm 0.3$ & $7.6 \pm 0.3$ & $7.7 \pm 0.1$ & $6.8 \pm 0.1$ & \\
\hline
\end{tabular}

T: week; G: group. Increase in total protein levels between T1 and T3 in G2, G3 and $\mathrm{G} 4(\mathrm{p}<0.05)$. Slow decrease in G1 and G2 during 12 weeks.

TABLE 3 - Albumin between groups (g/dl).

\begin{tabular}{lccccc}
\hline Albumin & T1 & T2 & T3 & T5 & T12 \\
\hline G1 & $3.0 \pm 0.5$ & $3.0 \pm 0.4$ & $2.9 \pm 0.4$ & $2.7 \pm 0.3$ & $2.6 \pm 0.3$ \\
G2 & $2.9 \pm 0.4$ & $3.6 \pm 0.2$ & $3.2 \pm 0.5$ & $2.5 \pm 0.3$ & $1.9 \pm 0.3$ \\
G3 & $2.5 \pm 0.2$ & $2.8 \pm 0.5$ & $2.7 \pm 0.5$ & & \\
G4 & $2.8 \pm 0.3$ & $2.6 \pm 0.4$ & $2.3 \pm 0.4$ & & \\
G5 & $2.7 \pm 0.4$ & $2.6 \pm 0.2$ & $2.4 \pm 0.2$ & $2.2 \pm 0.1$ & \\
\hline
\end{tabular}

T: week; G: group. Decrease in albumin in G2 during 12 weeks $(\mathrm{p}<0.05)$ and at T3 in $\mathrm{G} 4$ and $\mathrm{G} 5$ when compared to $\mathrm{G} 1$ and $\mathrm{G} 2(\mathrm{p}<0.05)$.

Total cholesterol and triglycerides decreased progressively during the entire follow-up in G1 and G2, statistically significant $(p<0.05)$ in $G 2$ when compared to G1. The mean levels of urea increased in G2 and G3 at T2 and T3 when compared to T1, and progressively in G2 to the end of the study (Tables 4 and 5). 
TABLE 4 - Total cholesterol between groups (mg/dl).

\begin{tabular}{lccccc}
\hline Total Cholesterol & T1 & T2 & T3 & T5 & T12 \\
\hline G1 & $91.3 \pm 6.4$ & $106.5 \pm 25.6$ & $96.0 \pm 23.5$ & $104.8 \pm 22.8$ & $82.2 \pm 13.8$ \\
G2 & $81.3 \pm 11.4$ & $85.5 \pm 21.7$ & $92.5 \pm 15.6$ & $75.7 \pm 17.3$ & $63.7 \pm 25.1$ \\
& & & & & \\
G3 & $79.7 \pm 15.4$ & $86.0 \pm 15.4$ & $79.2 \pm 20.7$ & & \\
G4 & $100.3 \pm 13$ & $92.5 \pm 12.2$ & $78.8 \pm 10.4$ & & \\
G5 & $102.8 \pm 18.9$ & $91.2 \pm 9.0$ & $83.3 \pm 9.3$ & $70.0 \pm 8.2$ & \\
\hline
\end{tabular}

T: week; G: group. Total cholesterol decreased progressively in G1 and G2, with G2<G1 ( $<<0.05)$.

TABLE 5 - Triglycerides between groups (mg/dl).

\begin{tabular}{lccccc}
\hline Triglycerides & T1 & T2 & T3 & T5 & T12 \\
\hline G1 & $72.8 \pm 18.9$ & $94.3 \pm 46.4$ & $82.7 \pm 34.3$ & $72.8 \pm 23.3$ & $84.8 \pm 29.3$ \\
G2 & $50.8 \pm 24.8$ & $28.8 \pm 9.1$ & $41.8 \pm 8.4$ & $43.0 \pm 24.9$ & $25.0 \pm 17.5$ \\
G3 & $40.8 \pm 9.2$ & $48.3 \pm 11.8$ & $47.7 \pm 18.0$ & & \\
G4 & $55.9 \pm 19.7$ & $62.3 \pm 16.2$ & $60.0 \pm 14.1$ & & \\
G5 & $63.0 \pm 18.3$ & $64.4 \pm 21.3$ & $72.0 \pm 20.8$ & $43.0 \pm 18.1$ & \\
\hline
\end{tabular}

T: week; G: group. Triglycerides levels decreased progressively in G2, with $\mathrm{G} 2<\mathrm{G} 1(\mathrm{p}<0.05)$ during 12 weeks.

The other biochemical variables did not showed any statistically significant variations between groups (bilirubin, creatinine, sodium, potassium and calcium).

\section{Animal survival}

Animals in G1 and G2 were sacrificed after 12 weeks (end of the study), as well as G3 animals, that reached the sacrifice criteria's between the third and fourth weeks after surgery. The cumulative survival in G1 and G2 ( $80 \pm 10$ days) was statistically significant $(\mathrm{p}<0.05)$ when compared to G3,G4 and G5. Cumulative survival between G4 and G5 was not statistically significant, with death of the animals related to acute rejection and systemic complications related to imunossupression respectively. Post-mortem examination revealed features in lungs related to pneumonia in G5 animals.

\section{Discussion}

Short bowel syndrome (SBS) has been extensively studied at experimental level due to the high mortality in patients undergoing large resections. The data obtained from experimental models of intestinal resection and transplantation in small animal not allow us to establish a correlations which occurs in humans.
The porcine model seems to be of choice for preclinical studies, related to the medium size, immunological and physiological characteristics similar to humans ${ }^{27}$ and easy acquisition.

Anesthesia in pigs requires a special care, especially in time-consuming or invasive surgeries, with the focus on the maintenance of hemodynamic and metabolic stability.

Hypotension and metabolic acidosis post-reperfusion were the main disorders in our study ${ }^{28}$, also observed by Siniscalchi et $a l .^{29}$, probably related to cardiovascular events after graft reperfusion.

Resections of $80 \%$ of small intestine was established in this study as the limit that should reproduce the SBS. In contrast to observed by Weale et al. ${ }^{5}$, the classic symptoms of SBS was observed in Group 2 and not in Group 1, where nutritional autonomy developed after four weeks, denoting the high capacity of intestinal adjustment.

Thus, resections up to $80 \%$ in pigs were not able to induce SBS, once the animals clinical follow-up showed a normal weight gain as observed in not operated pigs (weight control group).

However, weight loss was statistically significant in groups 3, 4 and 5 between the 1st and 3rd week, leading to the sacrifice of the animals in groups 2 and 3 in the 12th and 3 th week after surgery respectively. 
Similar results was observed by Kimura et al..$^{30}$. Intestinal resections including the ileum-cecal valve and right colon (G3) resulted in the worst form of SBS. The clinical signs and symptoms are similar to those observed in patients undergoing extensive resections with loss of ileum-cecal valve, called as "acute" SBS or ultra-short gut. The high mortality in this group after three weeks not allowed us to a better understanding of clinical implications of such resection, as was not our aim to use parenteral nutritional for nutritional disturbances correction. Ileum-cecal valve preservation in large intestinal resections slower the intestinal transit time; however, the exact understanding of their role and mechanisms on intestinal adaptation is still ${ }^{31}$.

Thus, Group 2 presented itself as the ideal model of "chronic" SBS, leading to a gradual weight loss and reaching the sacrifice criteria after three months.

Various surgical techniques for intestinal transplantation are described in animal models ${ }^{32}$.

The orthotopic model used in this study is similar to that used in humans. Despite feasibility, this model confers greater risks for early postoperative mechanical complications ${ }^{32,33}$.

The jejunostomy, as proposed by Chan et al. ${ }^{33}$, instead of ileostomy, decreased postoperative mortality resulting from excessive fluids loss, and allowed access to endoscopic examinations and biopsies.

The option for portal venous drainage of the graft was for physiological reasons and technical facility, as there is no necessary to a large extension of venous pedicle for anastomosis ${ }^{34}$.

Post-operative follow-up required a intensive clinical monitoring in Group 3, witch presented profuse diarrhea, while group 1 and 2 did not presented significant symptoms related to resection.

Animals in groups 4 and 5 presented complications related to acute cellular rejection and arising from the use of immunosuppressive drugs respectively.

Iintravenous fluids replacement and antibiotics were insufficient for correction of electrolyte and metabolic disorders as well as infectious complications after transplant.

Prophylactic antibiotic therapy was used in all animals and reintroduced in animals subjected to immunosuppression in view of the suggestive signs of infection as skin hyperemia, reduction on physical activity, food intake, and hematologic changes.

The use of analgesics was similar between groups. However, as the use of pain scores in experimental research is difficult for obvious reasons, daily assessment of likely sources of pain as surgical incision and local infections are mandatory ${ }^{25}$.

Among the proposed clinical evaluation, food acceptance was inadequate in groups 3, 4 and 5. With exception of Group 1, all animals have diarrhea until to the end of the study.

The presence of nonspecific signs and symptoms as skin hyperemia, decreased physical activity, low acceptance of food and diarrhea after intestinal transplantation may suggest the presence of rejection or infection, making necessary measures for early diagnosis and treatment .

A progressive decrease in total protein levels, albumin, total cholesterol, triglycerides, glucose and potassium between the 1st and 12th week were the main biochemical changes in Group 2, featuring a chronic malnutrition in this group.

Serum albumin levels did not changed in the remaining groups during the first three weeks and seems not being a sensitive monitor in the early stages of malnutrition. Serum urea levels increased in G2, G3, G4 and G5, being a sensitive monitor for all phases of assessment related to protein catabolism.

Despite the progress in surgical techniques and immunosuppression, clinical protocols for graft rejection monitoring for preventing the progression to more severe forms of rejection is still in the early stages of evolution ${ }^{35}$.

More recently, the quantification of serum citrulline was proposed as rejection monitor in intestinal transplants ${ }^{36}$, with significant correlation between citruline levels and graft rejection.

Conventional endoscopic procedures still depend of biopsies, as did not allow a more accurate assessment of changes in the early stages of rejection ${ }^{37,38}$.

However, severe acute rejection is easily identified by conventional endoscopy, but rarely reversible at this stage despite treatment ${ }^{39}$.

In this study, a positive predictive value of conventional endoscopy for severe acute rejection (presence of ulcerations) was $57 \%$ in Group 4, confirmed by histopathological evaluation, and normal endoscopic appearance in $43 \%$, not confirmed by histophatological analysis of biopsies or at necropsy.

Nonspecific changes suggestive of rejection classified as indeterminate were not identified at endoscopy in Group 5 for obvious reasons.

High resolution endoscopy with magnification of images enabled the view of "almost microscopic" details, becoming the method of election ${ }^{35}$.

Control of rejection is still a challenge in intestinal transplants, due to high graft immunogenicity.

FK 506 has been used as immunosuppressive drug ${ }^{40}$ integrating all protocols of immunosuppression in associations with other drugs to enhance their effects and to achieve the best therapeutic level with less toxicity and side effects.

The use of immunosuppression drugs in pigs demonstrated 
the difficulty in maintain the transplanted grafts due to accelerated drug metabolism, decreased systemic bioavailability and steroid resistance ${ }^{41}$, making greater doses necessary than those used in humans.

Frey et $a l .^{42}$ reported the need to double the dose of methylprednisolone and 10 times the dose of Cyclosporine for obtaining the same serum concentration of drug that is used in clinical transplants.

Micofenolate mofetil (MMF) has been proposed in various experimental and clinical protocols in association with tacrolimus $^{43,44}$.

We used micofenolato sodium, which differs from MMF by the presence of a capsule coating, which confer benefits to gastrointestinal tolerability.

The dosage was greater than that used in other studies ${ }^{44,45}$ and well tolerated without adverse effects.

The association with Tacrolimus was effective for prophylaxis of severe acute rejection, which was observed at 14 post-operative day in one animal and handled by adjusting the Tacrolimus dosage $($ serum level $=7.1 \mathrm{ng} / \mathrm{ml}$ ).

Non-immunosuppressed animals died as a result of severe acute rejection, confirmed by histophatological evaluation and at necropsy.

Increased survival was observed by others ${ }^{43-45}$, with the use of lower doses of Tacrolimus (serum levels between 5-15 ng/ml).

Infectious complications were the cause of deaths in this study, possibly triggered by high levels of immunosuppression. However, the proposed immunosuppression protocol was effective in preventing severe acute rejection, without a positive impact on animal survival.

Despite the results, this experimental model of SBS and intestinal transplantation in pigs allowed the basic knowledge about handling the animals and the immunosuppression after surgery.

\section{Conclusion}

The resection of $80 \%$ of small intestine in pigs is not suitable for short bowel syndrome induction. Intestinal transplantation with the proposed immunosuppression protocol was effective in prevent the occurrence of severe acute rejection, but inappropriate to increase recipients survival.

\section{Referências}

1. Koffeman GI, van Gemert WG, George EK, Veenendaal RA. Classification, epidemiology and aetiology. Best Pract Res Clin Gastroenterol. 2003;17(6):879-93. PMID: 14642855.
2. Lagnas A. Advances in small-intestine transplantation. Transplantation. 2004;77:S75-8. PMID: 15201690.

3. Dowling RH. Small bowel adaptation and its regulation. Scan J Gastroenterol. 1982;74 Suppl:53-74. PMID: 6815781.

4. Baksheev L, Fuller PJ. Humoral factors in intestinal adaptation. Trends Endocrinol Metab. 2000;11:401-5. PMID: 11091116.

5. Weale AR, Edwards AG, Bailey M, Lear PA. Intestinal adaptation after massive intestinal resection. Postgrad Med J. 2005;81:178-84. PMID: 15749794.

6. Messing B, Crenn P, Beau P, Boutron Ruault MC, Rambaud JC, Matuchanski C. Long term survival and parenteral nutrition dependency in adults patients with short bowel syndrome. Gastroenterology. 1999;117:1043-150. PMID: 10535866.

7. Chan S, McCowen KC, Bistrian BR, Thibaut A, Forse RA, Burke $\mathrm{P}$. Incidence, prognosis and etiology of end-stage liver disease in patients receiving home parenteral nutrition. Surgery. 1999;. 126:28. PMID: 10418589.

8. Goulet O, Ruemmele F. Causes and management of intestinal failure in children. Gastroenterology. 2006;130(2):S16-28. PMID: 16473066

9. Bianchi A. Longitudinal intestinal lengthening and tailoring: results in 20 children. J R Soc Med. 1997;90: 429-32. PMID: 9306995.

10. Canarelli JP. Réalisation expérimentale d'une valve iléo-colique conti-nen-te chez le rat. J Chir. 1986;123(1):39-44. PMID: 3958072

11. Blanco R, Niño J. Construction of a new intestinal valve. Dis Colon Rectum. 1994;37(6):606-9. PMID: 8200243.

12. Zurita M, Raurich JM, Ramirez A, Gil J, Darder J. A new neovalve type in short bowel syndrome surgery. Rev Esp Enferm Dig. 2004;96:110-18. PMID: 15255020.

13. Cowles RA, Lobritto SJ, Stylianos S, Brodlie S, Smith LJ, Jan D. Serial transverse enteroplasty in a newborn patient. J Pediatr Gastroenterol Nutr. 2007;45:257-60. PMID: 17667725.

14. Sudan D, Thompson J, Botha J, Grant W, Antonson D, Langnas A. Comparison of intestinal lengthening procedures for patients with short bowel syndrome. Annals Surg. 2007;246(4):593-601. PMID: 17893496.

15. Modi BP, Javid PJ , Jaksic T, Piper H, Langer M, Duggan C, Kamin D, Kim HB, First report of the international serial transverse enteroplasty data registry: indications, efficacy, and complications. J Am Coll Surg. 2007 Mar;204 (3):365-71. PMID: 17324769.

16. Duggan C, Piper H, Javid PJ, Valim C, Collier S, Kim HB, Jaksic T. Growth and nutritional status in infants with short-bowel syndrome after the serial transverse enteroplasty procedure. Clin Gastroenterol Hepatol. 2006;4(10):1237-41. PMID: 16904948.

17. Abu-Elmagd K, Reyes J, Todo S, Rao A, Lee R, Irish W, Furukawa $\mathrm{H}$, Bueno J, Murase N, Fung J, Starzl T. Clinical intestinal transplantation: new perspectives and immunologic considerations. J Am Coll Surg. 1998;186(5):512-27. PMID: 9583691.

18. Kato T, Tzakis AG, Gennaro S, Gaynor JJ, David AI, Bussoti A, Moon JI, Ueno T, Defaria W, Santiago S, Ueno T, Santiago S, Levi DM, Nishida S, Velasco ML, Mclaughlin G, Hernandez E, Thompson JF, Cantwell P, Holliday N, Livingstone AS, Ruiz Jr P. Intestinal and multivisceral transplantation in children. Ann Surg; 2006;243:756-66. PMID: 16772779.

19. Starzl TE, Rowe M, Todo S, Tzakis A, Porter KA. Transplantation of multiple abdominal viscera. . 1989; 261:1449-57. PMID: 2918640.

20. Pinna Ad, Weppler D, Nery J, Kato T, Ruiz P, Khan F, Levy D, Tzakis A. Intestinal transplantation at the University of Miami-Five years experience. Transplant Proc. 2000;32:1226. PMID: 10995922.

21. Tzakis AG, Kato T, Levi DM, Nery JR, Vianna R, Muller J, Ruiz P. Alemtuzumab (Campath-1H) combined with tacrolimus in intestinal and multivisceral transplantation. Transplantation. 2003;75:1512. PMID: 12792506. 
22. Mueller Ar, Pascher A, Platz KP, Braun F, Fandrich F, Rayes N, Kremer B. Immunosuppression following intestinal transplantation. Transplant Proc. 2004;36(2):325-8. PMID: 15050147.

23. Selvaggi $G$, Tzakis, AG. Intestinal and multivisceral transplantation: future perspectives. Front Biosci. 2007;12:4742-54. PMID: 17485410

24. Safford SD, Freemerman AJ, Safford KM, Bentley R, Skinner MA. Longitudinal mechanical tension induces growth in the small bowel of juvenile rats. Gut. 2005;54:1085-90. PMID: 15840689.

25. Swindle MM. Biology, handling, husbandry, and anatomy. In: Swindle MM, editor. Swine in the laboratory: surgery, anesthesia, imaging and experimental techniques. 2ed. New York: CRC Press; 2007.

26. Ruiz P, Bagni A, Brown R, Cortina G, Harpaz N, Magid MS, Reyes J. Histological criteria for the identification of acute cellular rejection in human small bowel allografts: results of the pathology workshop at the VII International small bowel transplant symposium. Transplant Proc. 2004;36:335-7. PMID: 15050150

27. Miller ER, Ullrey DE. The pig as a model for human nutrition. Ann Rev Nutr. 1987;7:361-82. PMID: 3300739.

28. Clark RM, Bakonyi Neto A, Bianchi EH. Evaluation of hemodynamic, metabolic and electrolyte changes after reperfusion in a porcine model of intestinal transplantation. Transplant Proc. 2010;42:87-91. PMID: 20172287.

29. Siniscalchi A, Piraccini E, Cucchetti A, Lauro A, Maritozzi G, Miklosova Z, Ravaioli M, Pinna AD, Faenza S. Analysis of cardiovascular, acid-base status, electrolyte, and coagulation changes during small bowel transplantation. Transplant Proc. 2006;38:1148-50. PMID: 16757291.

30. Kimura K, Larosa CA, Blank MA, Jaffe BM. Successful segmental intestinal transplatation in enterectomized pigs. Ann Surg. 1990;211(2):158-64. PMID: 2301995.

31. Collins J, Vicente Y, Georgeson K, Kelly D. Partial intestinal obstruction induces substantial mucosal proliferation in the pig. $\mathrm{J}$ Pediatr Surg. 1996;31:415-9. PMID: 8708915.

32. Kaneko H. Technical aspects of small bowel transplantation in the pig allograft model. Transplant Proc .1996;28(3):1843-4. PMID: 8658910

33. Chan KL, Guo WH, Tam PKH. Porcine small bowel transplantation with FK506 as a single immunosuppressant. Transplant Proc. 2001;33:2606-8. PMID: 20172287.

34. Alessiani M, Spada M, Vischi S. Total orthotopic small bowel transplantation in swine under FK 506. Transplant Proc. 1994;26(3):1606-8. PMID: 7518148.

35. Kato T, Gaynor JJ, Nishida S, Mittal N, Selvaggi G, Levi D, Moon J, Thompson J, Ruiz P, Madariaga J, Tzakis AG. Zoom endoscopic monitoring of small bowel allograft rejection. Surg Endosc. 2006;20(5):773-82. PMID: 16544078.

36. Pappas PA, Tzakis AG, Saudubray JM, Gaynor JJ, Carreno MR, Huijing F, Kleiner G, Rabier D, Kato T, Levi DM, Nishida S, Gelman B, Thompson JF, Mittal N, Ruiz P. Trends in serum citrulline and acute rejection among recipients of small bowel transplants. Transplant Proc. 2004;36:345-47. PMID: 15050154.
37. Hassanein T, Shade R, Soldevilla-Pico C, Tabasco-Minguillan J, Todo S, Tzakis A. Clinical and endoscopic features of rejection in small bowel transplant recipients. Transplant Proc. 1994;26(3):1413. PMID: 8029961.

38. Tabasco-Minguillan J, Weber K, Nelson F, Hutson W. Variability in the interpretations of endoscopic findings in patients with intestinal transplantation. Transplant Proc. 1996;28(5)2775-6. PMID: 8908053.

39. Ishii T, Mazariegos GV, Bueno J, Ohwada S, Reyes J. Exfoliative rejection after intestinal transplantation in children. Pediatr Transplant. 2003; 7:185-91. PMID: 12756042.

40. Starzl TE, Todo S, Fung J, Demetris AJ, Venkataramman R, Jain A. FK 506 for human liver, kidney and pancreas transplantation. Lancet. 1989;2(8670):1000-4. PMID: 2478846.

41. Yang WC, Schutz RD. Effect of corticosteroid on porcine leucocytes: age-related effects of corticosteroid inhibition on porcine lymphocyte responses to mitogen. Vet Immunol Immunopathol. 1986;13(1-2):19-29. PMID: 3765368.

42. Frey BM, Sieber M, Mettler D, Gänger H, Frey FJ. Marked interspecies difference between humans and pigs in cyclosporine and prednisolone disposition. Drug Metab Dispos. 1988;16(2):2859. PMID: 2898348.

43. Alessiani M, Spada M, Dionigi P, Arbustini E, Regazzi M, Fossati GS, Zonta A. Combined immunosuppressive therapy with tacrolimus and mycophenolate mofetil for small bowel transplantation in pigs. Transplantation. 1996;62:563-7. PMID: 8830816.

44. Spada M, Alessiani M, Ferrari P, Iacona I, Abbiati F, Viezzoli A, Regazzi MB, Bellinzona G, Dionigi P, Zonta A. tacrolimus and mycophenolate mofetil in pig small bowel transplantation: different protocols and outcome. Transplant Proc. 1997;29:1819-20. PMID: 9142286.

45. Viganó J, Abbiati F, Alessiani M, Zonta S, Doni M, Lusona B, Dionigi B. Incidence of graft rejection in small bowel transplanted pigs after immunosuppression withdrawal. Transplantation. 2006;38:1818-20. PMID: 16908291

\section{Correspondence:}

Alexandre Bakonyi Neto

Alameda Antonio Sartor, 220

18607-340 Botucatu - SP Brasil

a.bakonyi.neto@hotmail.com

Received: Oct 28, 2014

Review: Dec 26, 2014

Accepted: Jan 20, 2015

Conflict of interest: none

Financial source: Sao Paulo Research Foundation (FAPESP)

${ }^{1}$ Research performed at Experimental Laboratory, Department of Surgery and Orthopedics, Botucatu Medical School, State University of Sao Paulo (UNESP), Brasil. 